\title{
Hereditary spinal neurofibromatosis: a rare form of NF1?
}

\author{
M Poyhonen, E-L Leisti, S Kytölä, J Leisti
}

\begin{abstract}
We describe a family in which seven members in three generations were affected with a rare spinal neurofibromatosis. The affected adults showed, at the ages of $32,37,38$, and 61 , respectively, multiple spinal neurofibromas symmetrically affecting all spinal roots. Two patients were operated on for histopathologically proven cervical spinal neurofibromas. All patients had café au lait spots, one had several freckles in the axillary area, and two had possible dermal neurofibromas, but iris Lisch nodules were not present. Other signs of neurofibromatosis types 1 and 2 were absent. A linkage study of the family suggested close linkage to the NF1 locus and excluded it from the NF2 locus. The DNA analysis of histopathologically verified spinal neurofibromas in two patients showed no evidence of LOH at 17q11.2.

The findings in the present family, together with those in a family previously described, suggest a clinically distinct form of neurofibromatosis with extensive spinal neurofibromas and café au lait macules, which may be allelic to the NF1 gene.

$(\mathcal{M}$ Med Genet 1997;34:184-187)
\end{abstract}

Keywords: neurofibromatosis; NF; spinal neurofibroma.

Neurofibromatosis type 1 (NF1), also known as peripheral NF, or von Recklinghausen's disease, is an autosomal dominantly inherited, neurocutaneous disease. The gene responsible for NF1 is located on chromosome 17q11.2. The prevalence of NF1 is estimated to be 1:3500 in western populations. ${ }^{12}$ In 1991, Pulst $e t a l^{\beta}$ described a family with a previously unrecognised variant of classical neurofibromatosis characterised by spinal neurofibromas and café au lait spots in several generations, and another family with only spinal neurofibromas. Other signs of NF1, such as cutaneous neurofibromas, plexiform neurofibromas, freckles, or iris Lisch nodules, were absent. Hallmarks of NF2, such as vestibular schwannomas and juvenile cataracts, were also absent in both families. Linkage analysis with polymorphic DNA markers showed linkage to the NF1 locus in the first family and excluded it in the second family. Weinstock et $a l^{4}$ also reported eight patients with numerous spinal and peripheral tumours, but without the classical findings of NF1 or NF2. Here, we present a family with café au lait spots in seven people in three generations. MRI showed symmetrically distributed, extradural, intraspinal neurofibromas in the cervical, thoracic, and lumbar regions of the spine in all four adults. Linkage analysis with DNA markers showed close linkage with the NF1 gene.

\section{Methods}

All patients were examined clinically and three adults were seen by an ophthalmologist. MRI scan (Siemens Magnetom 1.0T) was performed on the brain and spine using $\mathrm{T} 1$ and T2 weighted images. DNA was extracted from blood leucocytes and specimens of neurofibromas according to standard procedures. Five polymorphic markers linked to $17 \mathrm{q} 11.2$ and three linked to $22 \mathrm{q} 12$ were assayed in this study. The markers were pHHH202/RsaI (D17S33), ${ }^{5} \quad$ EVI-20, ${ }^{4} \quad$ IVS27AC28.4, ${ }^{7}$ IVS38GT53.0, ${ }^{8}$ and pEW206/MspI (D17S57) for $17 \mathrm{q} 11.2$, and NF2CA-3, ${ }^{10} \mathrm{D} 22 \mathrm{~S} 280$, and $\mathrm{D} 22 \mathrm{~S} 281^{11}$ for $22 \mathrm{q} 12$. LOH was studied with intragenic microsatellite markers, EVI-20, IVS27AC28.4, and IVS38GT53.0, from two spinal neurofibromas that were confirmed by pathological examination.

Lod scores for the two point linkage analyses were calculated using the MLINK program (version 5.1) of the LINKAGE program package, ${ }^{12}$ using gene frequencies of 0.003 in $\mathrm{NF} 1$ and 0.0002 in NF2, and a penetrance value of $95 \%$. Female and male recombination rates and allele frequencies for all marker alleles were considered to be equal. ${ }^{13}$

\section{Results}

The family was brought to our attention following the examination of a 32 year old, apparently healthy female (fig 1, II.5) who has three children. Her clinical examination was unremarkable, except for the appearance of nine small, but larger than $15 \mathrm{~mm}$, light brown, café au lait spots on the back and both thighs. She also had one small tumour resembling a neurofibroma in the occipital subcutis. An ocular examination by a neuro-ophthalmologist showed no Lisch nodules or subcapsular lens opacities. Her brain MRI was normal but spinal MRI showed multiple neurofibromas located symmetrically on both sides and at all levels of the spine. The largest extramedullary tumours were compressing the cord in the $\mathrm{C} 5 / 6$ region In addition, multiple paraspinal neurofibromas were found symmetrically, at all levels of the lumbar spine. No scoliosis was observed. Her oldest child, a 4 year 2 month old girl (III.2), had no signs of NF, while the two youngest 
Table 1 Clinical features of families with spinal neurofibromatosis as compared with NF1 and NF2

\begin{tabular}{|c|c|c|c|c|c|}
\hline \multirow[b]{2}{*}{ Feature } & \multirow[b]{2}{*}{ Present family } & \multirow{2}{*}{$\begin{array}{l}\text { Family } 1 \text { of } \\
\text { Pulse et al }\end{array}$} & \multirow{2}{*}{$\begin{array}{l}\text { Total } \\
(n=11) \\
(\%)\end{array}$} & \multicolumn{2}{|c|}{ Published reports ${ }^{12182526}$} \\
\hline & & & & NF1 (\%) & $N F 2(\%)$ \\
\hline CLS & $6 / 6$ & $5 / 5$ & 100 & $>95$ & Rare \\
\hline Freckles & $1 / 6$ & $0 / 5$ & 17 & $>80$ & Rare \\
\hline Dermal neurofibromas & $\begin{array}{l}2 / 6 \text { (not } \\
\text { biopsied) }\end{array}$ & $0 / 5$ & 18 & $>90$ & Rare \\
\hline Spinal neurofibromas & $4 / 4$ & $3 / 4$ & 88 & $>5$ & Rare \\
\hline Spinal schwannomas & $0 / 4$ & $0 / 4$ & 0 & Rare & $>25$ \\
\hline Lisch nodules & $0 / 6$ & $0 / 4$ & 0 & $>90$ & Absent \\
\hline $\begin{array}{l}\text { Posterior subcapsular } \\
\text { lens opacity }\end{array}$ & $0 / 6$ & $0 / 4$ & 0 & None & 50 \\
\hline
\end{tabular}

children (III.3, III.4), a 1 year 4 month old girl and a 3 month old boy, both showed multiple café au lait spots, but no other signs of NF. MRI examination has not been performed on them (table 1).

The proband's mother (I.2) is a 61 year old female who has suffered from paraparesis and back pain for several years. Previous examination by CT has shown a thickening of the nerves in the lumbar region. At clinical examination, she was found to have multiple
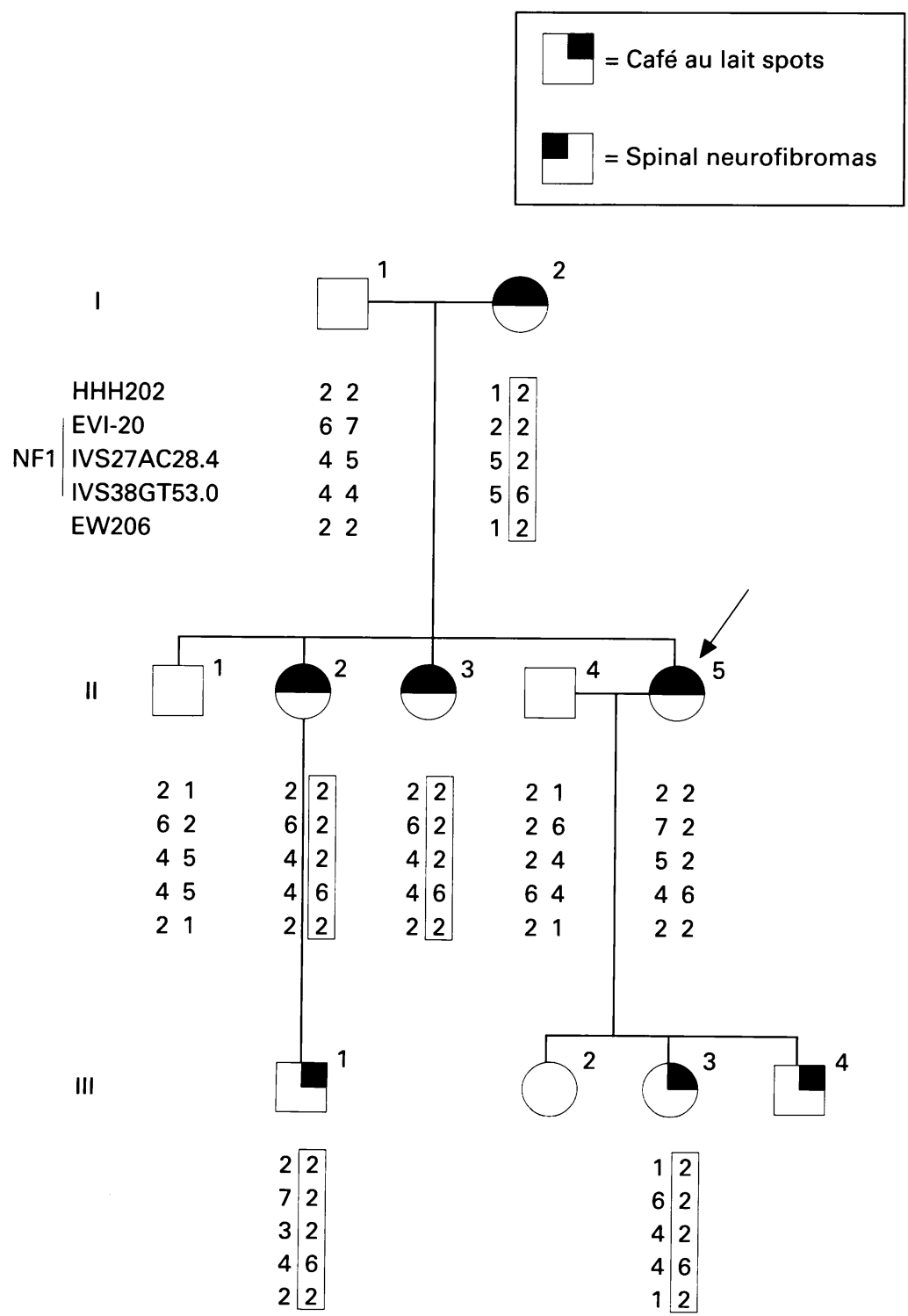

Figure 1 Pedigree of the family with spinal neurofibromatosis showing the segregation of chromosome haplotypes of the marker systems, which are listed on the left. The chromosome carrying the disease allele is boxed. café au lait spots (size over $15 \mathrm{~mm}$ ) and freckles in the axillary and inguinal regions, but no cutaneous neurofibromas or other signs of NF. Her ophthalmological examination showed no iris Lisch nodules or posterior subcapsular lens opacity. The neurological examination, the head circumference, and the blood pressure were all normal. Her brain MRI was normal. Spinal MRI showed several symmetrical nerve sheath neurofibromas at all levels of the spine. At the T6/7 level, she had a tumour $1 \mathrm{~cm}$ in size, which could be a dumb bell type of neurofibroma. She had several neurofibromas and duralectasias located in the lumbar spinal region.

The proband's sister (II.3) is a 37 year old female, who underwent surgery for a cervical spinal neurofibroma for the first time in 1989. She had complained about pain and weakness in the lower extremities and electric shock-like pains in the upper extremities, but no headaches. Upon clinical examination, she was found to have several café au lait spots (size over $15 \mathrm{~mm}$ ), but no freckles or other findings of NF. In addition, she has two small cutaneous neurofibroma-like tumours in the occipital region and two others at the level of the stomach on the right side of her body. She had mild macrocephaly and her blood pressure was normal. An ophthalmological examination showed no Lisch nodules, posterior subcapsular lens opacity, or fundus abnormalities. MRI of the brain of patient II. 3 brain showed a $5 \mathrm{~mm}$ tumour in the right frontal lobe and a suspected hamartoma in the cerebral peduncle. The spinal MRI showed multiple neurofibromas on both sides and at all levels of the cervical spine, with large tumours at $\mathrm{C} 1 / 2$, especially on the left side and in the C5/6 region, but the largest tumour was at $\mathrm{C} 6 / 7$, where extramedullary neurofibromas were growing from both sides into the spinal canal (fig 2) and compressing the cord. The C6/7 tumour was located at the same place where she had previously been operated upon. In the thoracic spine, she was found to have a few small extramedullary tumours. In addition, MRI showed multiple paraspinal neurofibromas on both sides and at all levels of the lumbar spine, with tumours growing into the spinal cord in the L3/4 region. MRI of patient II.3 showed several findings, especially in the spinal area (fig 2) and she has been reoperated on to remove cervical tumours from the $\mathrm{C} 5, \mathrm{C} 6$, and $\mathrm{C} 7$ regions, totally or partially. The histopathological examination showed typical neurofibromas. The patient was shown to be heterozygous for intragenic polymorphic markers, but no evidence of LOH was observed in the two spinal neurofibromas studied.

The proband's other sister (II.2) is a 38 year old, healthy female, but suffers from mild pain and weakness of the upper extremities. Her clinical examination showed six small café au lait spots, slight macrocephaly, and some pigmented naevi of the iris. No cutaneous neurofibromas, freckles, iris Lisch nodules, or other NF findings were found. MRI examination of the brain was normal, but MRI of the entire spinal cord showed several tumours. In 


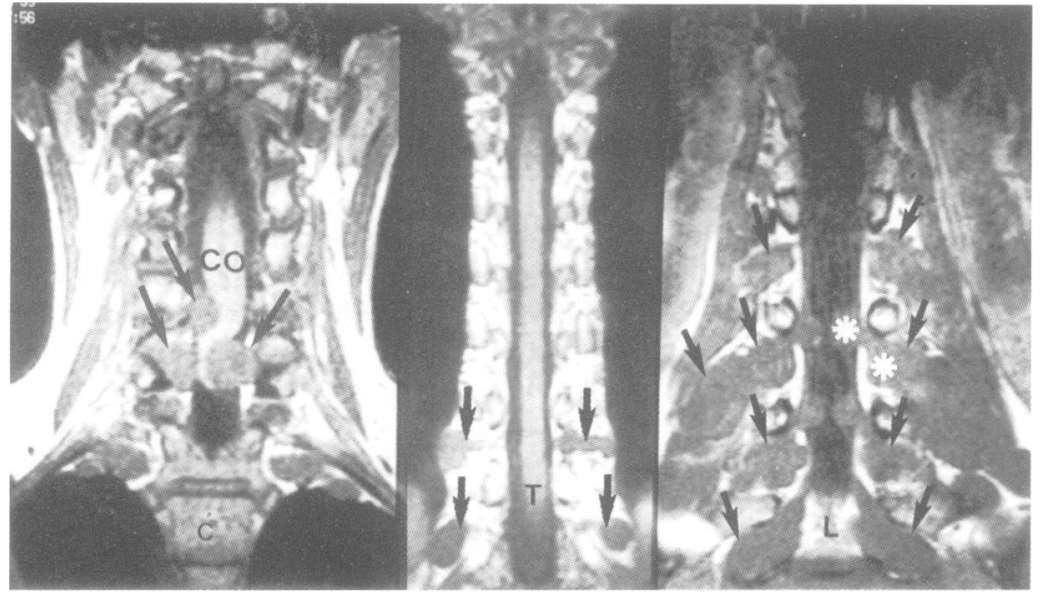

Figure 2 Coronal T1 weighted non-contrast MR images (SE, TR 500, TE 15, slice thickness $=3-5 \mathrm{~mm}$ ) of the cervical $(C)$, thoracic $(T)$, and lumbar $(L)$ spine of patient II.3. Several extradural and intralextraspinal neurofibromas (black arrows) can be seen bilaterally at several levels. The tumours compress the cervical cord (CO). The intra- and extraspinal components of a dumb bell neurofibroma are shown with white asterisks.

the cervical $\mathrm{C} 6 / 7$ and $\mathrm{C} 7 / \mathrm{T} 1$ regions, she has extradural and extramedullary tumours compressing the cord on the left side. In the lumbar region, nerve sheaths appeared thicker than normal and there were several nerve sheath neurofibromas. The cervical tumours in the C7-C8 region were removed totally or partially. Histopathological examination showed typical plexiform neurofibromas. The patient was shown to be heterozygous for intragenic polymorphic markers, but no evidence of $\mathrm{LOH}$ was observed in the spinal plexiform neurofibroma studied. Her 2 year 1 month old son (fig 1, III.1) is healthy, but has several large café au lait spots. MRI examination has not been performed on him.

The proband's 39 year old brother (fig 1, II.1) is healthy and is not known to have any signs of NF.

Linkage studies showed close linkage to the NF1 locus markers (lod score of $1.763(\theta=0)$ ) (table 2) and excluded linkage to the NF2 locus (lod score of $-4.941(\theta=0)$ ). Analysis of the two neurofibromas studied did not show any loss of heterozygosity ( $\mathrm{LOH})$ at $17 \mathrm{q} 11.2$ with the markers used.

\section{Discussion}

All of the four affected adults in the present family exhibit a distinct clinical entity of hereditary neurofibromatosis, consisting of extensively and apparently symmetrically distributed, histologically proven, spinal neurofibromas, in association with cutaneous café au lait spots and occasional axillary freckling, but no Lisch nodules. The sister of the proband (II.3) also showed an abnormal brain MRI, with a small frontal tumour and a possible

Table 2 Two point lod scores for linkage of markers to NF1 (Zmax maximum lod score, $\theta m=f$ estimated genetic distance)

\begin{tabular}{ll}
\hline$N F 1$ & Recombination fraction $(\theta m=\theta f)$ \\
\hline versus & Zmax \\
pHHH202 & 0.882 \\
EVI-20 & 0.882 \\
IVS27AC28.4 & 1.763 \\
IVS38GT53.0 & 0.882 \\
pEW206 & 0.882 \\
\hline
\end{tabular}

hamartoma. Freckles were seen in the mother (I.2) and probable cutaneous neurofibromas were found in the proband (II.5) and in one of her sisters (II.3). Linkage studies suggest linkage to the NF1 locus, while linkage to the NF2 locus was excluded, signifying that spinal neurofibromatosis may be an allelic form of NF1. Café au lait spots were also found in three of the younger affected children, whose spinal manifestations have not been evaluated. This family seems to be similar to the one described by Pulst $e t a^{\beta}$ where five affected members in four generations showed CLS, spinal neurofibromas, and linkage to the NF1 gene (table 1).

The patients' signs also meet the NIH criteria for NF1 (café au lait spots and multiple neurofibromas). The diagnostic criteria for NF1 are met if two or more of the following are found: six or more café au lait macules; two or more neurofibromas of any type, or one plexiform neurofibroma; multiple freckles in the axillary or inguinal regions; optic glioma; two or more Lisch nodules (iris hamartomas); a distinct osseous lesion, such as sphenoid dysplasia or thinning of the bone cortex with or without pseudarthrosis; a first degree relative (parent, sib, or offspring) who meets the above criteria for NF1. ${ }^{14} 15$ They did not show clinical features characteristic of NF2, such as vestibular schwannomas or posterior subcapsular lens opacity. ${ }^{15-17}$

Benign spinal nerve sheath tumours occur on nerve roots in neurofibromatosis types 1 and 2 or sporadically. ${ }^{18-21}$ In NF1, spinal neurofibromas are described as symptomatic findings in only about $5 \%$ of patients, ${ }^{1-3} 2223$ while in a spinal MRI study of $28 \mathrm{NF} 1$ patients, ${ }^{19}$ spinal neurofibromas were seen in $10 / 28(36 \%)$ of them, with only two patients having clinical symptoms. In our own study of 42 adult NF1 patients (Leisti et al, in preparation), MRI of the spine showed $16 / 42$ (38\%) patients with spinal neurofibromas. Two patients showed neurofibromas all along the spine, but they also presented with extensive subcutaneous neurofibromas and other clinical manifestations of NF1. Thus, spinal neurofibromas occur more often than suspected by clinical examination. A wide and symmetrical distribution of spinal neurofibromas is, however, rare ${ }^{19-21}$ and the presence of multiple spinal neurofibromas affecting all spinal roots symmetrically in all the adult members of the family studied is exceptional. Such a finding is generally atypical of NF, where the occurrence of a single defect is not predictable, as seems to be the case with spinal neurofibromas in this family. The findings suggest that the gene defect in this family has a special effect on neural crest cells and their precursors in the nerve roots. According to our study, this is not associated with $\mathrm{LOH}$ at $17 \mathrm{q} 11.2$, a phenomen only rarely reported in neurofibromas in NF1. ${ }^{64}$

In cases of suspected spinal neurofibromas it seems advisable to perform spinal MRI on all relatives suspected of having this condition, especially if they have NF1 without Lisch nodules. 
We would like to thank the family members for their enthusiasm for this work.

1 Riccardi VM. Neurofibromatosis: phenotype, natural history and pathogenesis. 2nd edition. Baltimore: Johns Hopkins and pathogenesis. 2nd

2 Huson SM, Hughes RAC. The neurofibromatoses: a pathogenetic and clinical overview. London: Chapman and Hall, 1994

3 Pulst S-M, Riccardi VM, Fain P, Korenburg JR. Familia spinal neurofibromatosis: clinical and DNA linkage analysis. Neurology 1991;41:1923-7.

4 Weinstock A, Cohen BH, Moorjani B, Ruggerieri P, Rothne D. Spinal neurofibromatosis: NF1, NF2 or other? The NNFF International Consortium for the Molecular Biology of $N F 1$ and $N F 2,1995$, abstract.

5 Ainsworth PJ, Rodenhiser DI. Rapid nonradioactive detection by PCR of pHHH202/RsaI RFLP linked to neurofibromatosis type I. Am $\mathcal{f}$ Hum Genet 1991;49:1098-9.

6 Colman SD, Williams CA, Wallace MR. Benign neurofibromas in type 1 neurofibromatosis (NF1) show somatic deletions of the NF1 gene. Nat Genet 1995;11:90-2

7 Charrow J, Listernick R, Ward K. Autosomal dominant multiple café-au-lait spots and neurofibromatosis-1: evidence on non-linkage. Am $\mathcal{F}$ Med Genet 1993;45:606-8.

8 Lázaro C, Gaona A, Estivill X. Two CA/GT repeat polymorphisms in intron 27 of the human neurofibromatopolymorphisms in intron 27 of the human neurofib

9 Lázaro C, Gaona A, Xu G, Weiss R, Estivill X. A highly informative CA/GT repeat polymorphism in intron 38 of the human neurofibromatosis type 1 (NF1) gene. Hum Genet 1993;92:29-30.

10 Bourn D, Strachan T. Highly polymorphic dinucleotide repeat at the NF2 gene. Hum Genet 1995;95:712.

11 Gyapay G, Morissette J, Vignal A, et al. The 1993-94 Généthon human genetic linkage map. Nat Genet 1994;7:246 339.

12 Lathrop GM, Lalouel JM. Easy calculations of lod scores tisks on small computers. Am $\mathcal{F}$ Hum Genet 1984;36:460-5.

13 Rodenhiser DI, Ainsworth PJ, Coulter-Mackie MB, Sing SM, Jung JH. A genetic study of neurofibromatosis type 1
(NF1) in south-western Ontario. II. A PCR based approach to molecular and prenatal diagnosis using linkage. $\mathcal{F}$ Med Genet 1993;30:363-8

14 Stumpf DA, Alksne JF, Annegers JF, et al. Neurofibromatosis conference statement. National Institutes of Health Consensus Development Conference. Arch Neurol 1988;45:575-8.

15 Mulvihill JJ, Parry DM, Sherman JL Pikus A, KaiserKupfer MI, Eldridge R. Neurofibromatosis 1 (Recklinghausen disease) and neurofibromatosis 2 (bilateral acoustic neurofibromatosis). NIH conference. An update. Ann Intern Med 1990;113:39-52.

16 Louis DN, Ramesh V, Gusella JF. Neuropathology and molecular genetics of neurofibromatosis 2 and related tumours. Brain Pathol 1995;5:163-72.

17 Evans DGR, Huson SM, Donnai D, et al. A clinical study of type 2 neurofibromatosis. $Q \mathcal{F}$ Med 1992;48:603-18.

18 Viskochil D, Carey JC. Alternate and related forms of the neurofibromatoses. In: Huson SM, Hughes RAC, eds. The neurofibromatoses: a pathogenetic and clinical overview. London: Chapman and Hall, 1994:445-74.

19 Egelhoff JC, Bates DJ, Ross JS, Rothner AD, Cohen BH. spinal MR findings in neurofibromatosis types 1 and 2 . A7NR 1991;13:1071-7.

20 Halliday AL, Sobel RA, Martuza RL. Benign spinal nerve sheath tumours: their occurrence sporadically and in neurofibromatosis types 1 and 2. F Neurosurg 1991;74:248

21 Seppälä MT, Haltia MJJ, Sankila RJ, Jääskeläinen .JE, Heiskanen O. Long-term outcome after removal of spinal neurofibroma. 7 Neurosurg 1995;82:572-7.

22 Huson SM, Harper PS, Compston DAS. Von Reckling hausen neurofibromatosis. A clinical and population study in south-east Wales. Brain 1988;111:1355-81

23 von Deimling A, Krone W, Menon AG. Neurofibromatosis type 1: pathology, clinical features and molecular genetics. Brain Pathol 1995;5:153-62.

24 Shen $\mathrm{MH}$, Harper PS, Upadhyaya M. Molecular genetics of neurofibromatosis type 1 (NF1). 7 Med Genet 1996;33:2 